\title{
FUTURE SCENARIOS TO INSPIRE INNOVATION
}

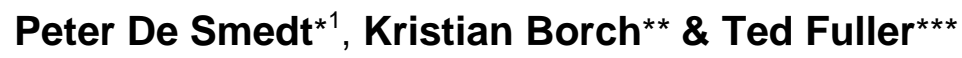 \\ *SVR - Research Centre of the Flemish Government - Boudewijnlaan 30, B-1000 Brussels, BE \\ ** Department of Management Engineering - Technical University of Denmark, DK \\ *** Faculty of Business and Law - University of Lincoln, UK
}

Pre-submission version of paper submitted for review to Technological Forecasting and Social Change

Feb 2012.

\begin{abstract}
In recent years and accelerated by the economic and financial crisis, complex global issues have moved to the forefront of policy making. These grand challenges require policy makers to address a variety of interrelated issues, which are built upon yet uncoordinated and dispersed bodies of knowledge. Due to the social dynamics of innovation, new socio-technical subsystems are emerging, however there is lack of exploitation of innovative solutions. In this paper we argue that issues of how knowledge is represented can have a part in this lack of exploitation. For example, when drivers of change are not only multiple but also mutable, it is not sensible to extrapolate the future from data and relationships of the past. This paper investigates ways in which futures thinking can be used as a tool for inspiring actions and structures that address the grand challenges. By analysing several scenario cases, elements of good practice and principles on how to strengthen innovation systems through future scenarios are identified. This is needed because innovation itself needs to be oriented along more sustainable pathways enabling transformations of socio-technical systems.
\end{abstract}

\section{Highlights}

- Grand challenges bringing the social dimension of innovation in the picture

- Investigating the role for futures thinking and scenarios to inspire innovation

- Future scenarios as a tool for orienting innovation systems

\section{Keywords}

Reflexive inquiry, Innovation, Scenario practice, Grand Challenges

\section{Introduction}

In the context of this paper, future scenarios can be seen as narratives set in the future to explore how the society would change if certain trends were to strengthen or diminish, or various events were to occur. Future scenarios substantially differ from predictions, i.e., extrapolations or trends, substituting the criterion of plausibility for probability (Harries, 2003). Scenarios are not equivalent to images of the future, but they consist of images of the future. Images of the future

\footnotetext{
${ }^{1}$ Corresponding author: T: +32 25535785 E: +32 $25535808 \quad$ peter.desmedt@dar.vlaanderen.be
} 
are snapshots of future states, whereas scenarios consist of a logical sequence of images of the future (Greeuw et al., 2000).

\subsection{Developing and using future scenarios}

Scenario analysis is practiced across many domains and is not restricted to specialised futurists or scenario specialists. Developing and using scenarios can contribute at various levels of society by generating appropriate inputs for planning and decision-making and by facilitating dialogues between various stakeholders (Becker, 1983). The value of the scenario exercise depends on the ways in which the resulting insights are implemented in on-going and forthcoming actions. However, the explicit and direct uses of scenarios in predefined decisionmaking contexts are just part of a broader social process (Da Costa et al., 2008). Also important indirect and diffuse links exist between developing and using scenarios and orienting innovation systems and research priorities (inspired by Andersen et al., 2007, p.8-9):

- developing and using future scenarios may contribute to society's strategic intelligence by stimulating future oriented thinking and by widening the perspectives and knowledge base of researchers, policy-makers and business decision-makers

- developing and using future scenarios can be useful in creating a common language and understanding between the various interest groups

- developing and using future scenarios can create and support a systemised negotiation process among key stakeholders (social actors)

- developing and using future scenarios can be helpful in engaging decision-makers in specific issues, legitimating a chosen course of action, and supporting fruitful debates among stakeholders

Although the use of scenarios has gained much adherence, its subjective and heuristic nature leaves many academics and decision-makers uncomfortable (Chermack, 2005). How do we know whether we have credible and salient scenarios? And how does developing and using scenarios lead to the expected direct and indirect inputs for orienting innovation systems? These concerns are legitimate and the use of scenarios would gain in academic standing if more research were conducted on their comparative performance and underlying theoretical premises (Chermack, 2005). Whilst the scenario literature makes explicit the methodological differences and similarities of various approaches, it tends to pay little attention to the underlying epistemological assumptions (Wilkinson \& Eidinow, 2008). For example, scenarios that imaginatively represent plausible futures will meet resistance if they are used as predictions.

\subsection{Grand challenges}

The aim of this paper is to initiate a discussion on how scenario analysis can help to better cope with the grand challenges and to disclose some principles by which scenario processes can inspire innovation. Today's grand challenges - from climate change to unemployment and poverty - go beyond economic and social policies (Boden et al., 2010). The recent economic crisis reminds us of the importance of mobilising science, technology and innovation not solely for generating economic benefits, but also for anticipating and responding to the grand challenges (OECD, 2011). At a strategic level, the European Union took up this challenge via the Innovation Union Flagship Initiative as part of the Europe 2020 strategy launched in 2010. This initiative is a strategic approach integrating research and innovation instruments and actors to tackle the "innovation emergency" Europe is facing (EC, 2011a, p1). 
From a scientific perspective, it is accepted that the future is an essential element of strategy. For example, Hamel and Prahalad (1994) emphasise that strategy should draw up consistent visions of the future. In addition, several scholars state that scenarios constitute a major tool for considering the future in strategic planning (Porter, 1985, Godet, 1990, Wilson, 2000, Lindgren \& Bandhold, 2003, Bradfield et al., 2005, Ringland, 2010).

Grand challenges are usually interrelated and operating at a global scale (Cagnin et al., 2011). Often it is not clear what the real causes are and different policy options are competing, causing shifts in problem perception and priority setting. One result of the above described complexity is a type of uncertainty about the future, an uncertainty whose distinctive feature is disagreement amongst experts and stakeholders about the long-term consequences of present-day innovations (Webster, 1999). In addition, uncertainty increases as policy targets move progressively further from the present and it is uncomfortable: fear of the unknown generates resistance to change (Linstone, 1973). But also efforts to control, manage, and engineer the future produce increased uncertainties (Adam, 2006). For instance, developments in science and technology have a strong potential to influence social change. There are, however, many reasons why the practical use of scientific knowledge and technology varies widely between countries. Societies differ, economies differ, and governments deal with international scientific developments in different ways through the policies they pursue (Timmermans, 2001). This analysis indicates that policy and systems of innovation are shaped by social, cultural and political power as well as by technological rationalism and such indeterminism makes systemic approaches to innovation policy far from linear or predictable.

The traditional concepts and models of innovation are not always adequate to embrace the complexity for addressing the grand challenges (Cagnin et al., 2011; OECD 2011). Grand challenges require that policy makers address a variety of interrelated issues, which are built upon as yet uncoordinated and dispersed bodies of knowledge. The modes of knowledge production have already experienced considerable changes. It has been well documented that the innovation process is regarded as interactive including a multitude of short-term and longterm feedback loops between the different stages of the innovation process (Carlsson et al., 2002; OECD, 2011). Looking at the grand challenges, innovations are not only contributing to the solutions. Innovations in the past have been also part of the current unsustainable trends. Therefore innovation research needs increasingly be oriented towards the challenges presented by environmental complexity and socio-economic turbulence (Rickards, 2003).

In order to investigate how scenario analysis can help to better cope with the grand challenges and inspire innovation, we analyse several scenario exercises to better understand the role future scenarios can play as a tool for orienting innovation systems. The remaining sections of this paper are organised as follows: Section 2 sets out the methodology of how we used reflexive inquiry to analyse the scenario case studies. Section 3 describes how we conceptualise inspiring issues and paradigms from different scientific disciplines such as business and innovation research, futures studies, sociology and policy analysis. These concepts and paradigms are then used to analyse the selected scenario case studies. For example, we looked how the applied or perceived modes of thinking about the future and multiple stakeholder values are initiating enablers or barriers for the scenario process. In this paper we argue that this kind of reflexive inquiry can and does provide a sound basis for challenging current practice, for learning from experience and for better articulating our underlying theoretical premises. The outcomes of this inquiry are presented in Section 4 including also implications for practitioners by elaborating elements of good practice and areas of improvement. In Section 5, we further discuss our findings addressing how scenario practice can orientate innovation systems in the view of the grand challenges. Finally, in Section 6 we summarise our findings and conclude with some points of departure for further research. 


\section{Material and methods}

How can we learn about orienting innovation systems from future scenario practice? We use the word "practice" to describe the implementation or execution of a concept, plan, methodology or theory. Most practice is based on a set of theories or assumptions. Sometimes those theories are explicit, most often they are implicit. The connection between practice and theory (unlike that between theory and practice) has traditionally been ignored, to the detriment of both (Gunderson et al., 2007). Reflexive inquiry draws on a social constructionist view of the world and provides a powerful approach that offers insights for academics and practitioners into how we constitute knowledge and realities in our thinking and research practice (Cunliffe, 2003). Reflexivity as a methodology (Alvesson \& Sköldberg, 2000), questions representation by suggesting that we are constantly constructing meaning and social realities as we interact with others and talk about our experience. We therefore cannot ignore the situated nature of that experience and the cultural, historical, and linguistic traditions that permeate our work (Cunliffe, 2003). This means that practice, such as scenario practice, is rooted in a particular moment and place.

In accordance with Cunliff (2003) and to be consistent with reflexive inquiry, we first have to deconstruct scenario practice. In order to do so, three complementary questions on policy change (after De Smedt, 2006) are applied to analyse the case studies:

(i) How can developing and using future scenarios present a window of opportunity to effectively drive decisions?

(ii) How can developing and using future scenarios enhance the legitimacy for action?

(iii) How can developing and using future scenarios provide evidence to decision-makers empowering the stakeholders involved?

The three questions represent a specific perspective linking action and decision-making with issues of (i) emergence, i.e. window of opportunity; (ii) legitimacy, i.e. truth claims; and (iii) empowering, i.e. stakeholder values (De Smedt, 2006). This questioning takes then the form of a 'turning back' on knowledge, truth claims, language, and representation to make them more transparent (Cunliffe, 2003, p985 after Lawson 1985).

The empirical evidence is based on a sample of 17 scenario projects (see Appendix 1 . for an overview of the cases). This paper reports on the reflexive inquiry that originates from several workshops with scientists and practitioners where the case studies have been articulated and analysed in their context as part of the Cost Action A22 network ${ }^{2}$. In doing so, the workshops allowed for a systematic ex-post evaluation of similarities and differences between the chosen scenario projects. In the context of this paper, we will argue that this process of reflexive inquiry will provide the basis for creating new insights and adapting our underlying theoretical premises.

\footnotetext{
${ }^{2}$ The Cost Action A22 network was a four year programme (2004-2007) entitled "Foresight Methodologies - Exploring new ways to explore the future" and funded by the Individuals, Societies, Culture and Health technical committee of the European Cooperation in the field of Scientific and Technical Research (Cost). The programme was operationalised through a series of eight workshops, followed by an open scientific conference in July 2007 . The main research questions were: What methodological issues are salient in relation to the identification of emerging trends and change?, How commensurable are different modes of modelling and other forms of dynamical representation? How can different communities of practice interact in an overall productive and interested way?
} 


\section{Concepts of innovation, futures thinking and scenarios}

\subsection{Innovation systems}

Innovation involves the application of new ideas - or the reapplication of old ideas in new ways to develop better solutions to our needs (Coates, 2003). Innovation is invariably a cumulative, collaborative activity in which ideas are shared, tested, refined, developed and applied (Leadbeater, 2008). The concept of national innovation systems is rooted in evolutionary economic theorizing on socio-technical change. It was introduced and elaborated, among others, by Nelson \& Winter (1977), Lundvall (1992) and Freeman (1995). The development of innovation theory over the past decades has involved a major reformulation, with innovation no longer seen primarily as a process of discovery, i.e. new scientific or technological principles, but rather as a non-linear process of learning (Mytelka \& Smith, 2002). An innovation system is also not static but evolves with alterations in the content of technologies and products as well as in the relationships among various other innovation systems. Due to the socially dynamic characteristic of innovation (Sternberg et al., 2003), new socio-technical (sub)systems will emerge over time (Carlsson et al., 2002). By consequence, innovation systems are described as networks of actors and institutions that develop, diffuse and use innovations (Edquist, 2007). Hence, innovation leads to change only to the extent that agents are successful in taking advantage of the opportunities, i.e. agents need to develop capabilities (Carlsson and Stankiewicz, 1991).

Innovation in the 21st century differs from the model embraced in the last century (i.e. profitoriented and nationally targeted) with a linear, technological and deterministic characteristic (OECD, 2011). Our understanding of the unpredictable inter-dependency of multiple forces means that more experimental approaches to creating new solutions are necessary. Thus it is through trial-and-errors and learning-by-doing experiments that new solutions can be found to grand challenges. Hence, the social dimension in innovation should be acknowledged as a legitimate research area and linkages with social systems of innovation and social innovation stakeholders should be strengthened so that innovation experiments include the inherent social dimension within the research community (OECD, 2011).

Although the innovation process is now much more open and receptive to social influences, further progress calls for a greater involvement of stakeholders who can introduce the necessary capabilities and interests in research and innovation to address the grand challenges. For instance, Hekkert and colleagues (2007) highlight that stimulating knowledge flows (alone) is not sufficient to induce technological change and economic performance. There is a need for stakeholders to exploit this knowledge in order to create new business opportunities. This stresses the importance of stakeholders as sources of innovation, sometimes overseen in the, more macro-oriented, nationally or sector oriented innovation system approaches. The required characteristics of the new mode of public involvement are challenging: long-term forward-looking intervention, inter-ministerial, demand-side instruments combined and co-ordinated with supplyside instruments, participative, and based on foresight (OECD, 2011).

\subsection{Futures thinking}


Futures thinking is used for medium to long-term strategic analysis and planning. According to Jørgensen (in press, citing Dreborg, 2004), there are three modes of thinking about the future, each with their own methodologies - the predictive, the eventualities and the visionary mode of thinking (see Table 1 for a more elaborate description).

Table 1: Modes of thinking about the future

\begin{tabular}{lll}
\hline Mode of thinking about the future & $\begin{array}{l}\text { Type of futures in } \\
\text { focus }\end{array}$ & Characteristics \\
\hline The predictive mode of thinking & Probable futures & $\begin{array}{l}\text { Working with indications of what } \\
\text { will happen. Trying to find the } \\
\text { most likely development }\end{array}$ \\
The eventualities mode of thinking & Possible futures & $\begin{array}{l}\text { Openness to several different } \\
\text { developments }\end{array}$ \\
The visionary mode of thinking & Preferable futures & $\begin{array}{l}\text { Envisioning how society can be } \\
\text { designed in a better way }\end{array}$ \\
\hline
\end{tabular}

Source: adapted from Jørgensen (in press)

As highlighted in Table 1 , the different modes of thinking imply a focus on a different representation of the future. Representations of the future can be seen as metaphorical descriptions. Usually, these representations are mental images, but they can also be external representations, such as pictures or textual imagery (Beers et al., 2010).

One of the often-overlooked elements in the innovation process that hinders smooth communication and interaction within emergent networks is time (Selin, 2006). Following the work of Barbara Adam (Adam, 2006), time has many meanings beyond 'clock time'. Adam argues that the meaning of time is socially constructed and that such meaning is performative. Futurists are of course used dealing with short, medium and long-term perspectives, but it has been shown that differences in the construction of time play a significant role in the construction of meaning about the future (e.g. of nanotechnologies: Selin, 2006). The generic methodological requirement from this perspective is an explicit account of the construction of time within the context of the study at hand. For instance, time is considered to be historically and culturally specific. Different historical periods, different cultures, and different stages of the lifecycle all display different relationships to time. This means that situations are rooted in a particular moment and place and seen through the perspective of a certain set of lenses (Aaltonen, 2009).

\subsection{Scenario practice and related techniques}

Reflecting the uncertain threats of the cold war, the development of scenario practice as a methodology for planning and decision-making probably started more than half a century ago in the field of war game analysis. The Rand Corporation in the US became one centre for scenario thinking and Herman Kahn, who joined Rand, explored the application of systems analysis and game theory in order to encourage 'thinking the unthinkable' (Wilkinson \& Eidinow, 2008). Meanwhile in France, Gaston Berger was starting to use scenarios to explore the long-term political and social future. He founded the Centre d'Etudes Prospectives and his approach to scenarios was primarily normative, i.e. scenarios intended to provide a guiding vision of the 
future for policy makers (Marchais-Roubelat \& Roubelat, 2011). Scenario building and planning was further developed for management purposes, for example through the works of Pierre Wack, Peter Schwartz and many others (Wilkinson \& Eidinow, 2008). Since then, scenario approaches have continued to evolve and their use seems to be increasing again (van Notten et al., 2003; Bradfield et al., 2005, Van Asselt, 2010).

Developing and using scenarios is a professional practice to support significant decisions, and therefore it needs to be more assured of its claims to knowledge (methodology). For instance, forecasting and modelling methods have a focus on what is known and what is unknown. This can encompass 'What is likely', in terms of probabilities for example, but it is still essentially working in terms of the same basic known-unknown dichotomy (Wilkinson \& Eidinow, 2008). In contrast, explorative scenarios deal with different kinds of knowledge, ignorance and uncertainty, for example, socially constructed ignorance or 'uncomfortable knowledge' (Rayner, 2006).

The identification of the motivation behind any scenario exercise appears to underpin the scenario typology described by Borjesön et al., (2006) which reviews many other typologies before suggesting an alternative comprising three categories and six types. The categories arise from the kinds of question that a scenario user might use about the future: What will happen? What can happen? How can a specific target be reached? Each of these questions can be seen to evoke the motivation of a particular approach to scenarios. For example, in this typology "What will happen?" scenarios lead to predictive scenarios, in effect, forecasts, which look at what will happen as the likely development occurs. By contrast, "What can happen?" scenarios are normative scenarios - concerned with achieving particular future objectives - which lead to preserving and transforming scenarios. Preserving scenarios are used when the target can be met within an existing structure, while Transforming scenarios feature a form of backcasting, asking what would need to be changed for the target futures to be achieved.

Although most reviews of scenario techniques distinguish between quantitative and qualitative techniques, the boundaries between approaches have become increasingly blurred by techniques that make use of both kinds of methods and information (Wollenberg et al., 2000). Hence, our brief overview of scenario techniques in the next paragraphs of this section is not intended to provide a comprehensive classification or typology. Merely, its role is to describe the variety of current techniques that are relevant for this paper.

The concept of the multiple-axes method is based on one of the approaches used by Pierre Wack (Schoemaker, 1995). It generates four contrasting scenarios relevant to a particular area of interest, which may be geographic or thematic, by placing a major factor influencing the future of the issue being investigated on each of axes, which cross to form four quadrants if two axes are used. The factors chosen for the axes should be high-impact, high-uncertainty, to ensure that the four spaces defined by their intersection are clearly differentiated. These spaces are then developed into scenario narratives, reflecting the influence of other events and trends in addition to those represented on the two axes.

Back-casting, inspired by the early work of Lovins (1976), starts with defining a desirable future and then works backwards to identify policies and programs that will connect the future to the present. Back-casting scenarios explore the preconditions that could lead to this desirable future, including a palette of strategies to reach this situation (Rotmans et al., 2000).

The concept of roadmapping has its roots in science and technology planning (Phaal et al., 2001). A science or technology roadmap is like a highway roadmap that describes how one might proceed from a starting point to a final destination expressed as a vision. Like a highway roadmap shows the intersections between roads, a science or technology roadmap also shows the intersections between scientific steps or technologies (Gordon, 2003). A roadmap can take 
various forms, but generally comprises a time-based chart together with a number of layers, which provides a means to link technology and other resources to future products, as well as to innovation objectives and milestones (Phaal et al., 2001).

The delphi-method is developed as a systematic, interactive forecasting method which relies on a panel of experts. Delphi method is based on the assumption that group judgments are more valid than individual judgments. It is a method for structuring a group communication process so that the process is effective in allowing a group of individuals, as a whole, to deal with a complex problem. Key elements to accomplish this structured communication are: feedback of individual contributions of information and knowledge; an assessment of the group judgment or view; some level of opportunity for individuals to revise views; and some degree of anonymity for the individual responses (Linstone \& Turoff, 2002). This technique is often used in national foresights to guide innovation and national research policies (Webler et al., 1991; Gavigan \& Scapolo, 1999; Georghiou et al., 2008).

All the above describe approaches to futures thinking during which scenarios are produced or used or both. For example Delphi studies use micro-scenarios, road-maps and back-casting use end-point states, while most of the other techniques described produce narratives or images of alternative future states. These types of approaches are typical of those used in the projects listed in Appendix 1 which were used for empirical analysis in this paper.

\section{Results and implications}

The value of scenarios lies in the robustness of the claims to knowledge arising. As this knowledge is (socially) constructed, an explicit reflexive account of the production of that knowledge is a methodological necessity, as it will reveal significant choices underlying the presented scenarios (Fuller \& De Smedt, 2008). To structure our research, the scenario cases are evaluated using the three complementary questions on policy change mentioned in Section 2 (material and methods). An overview of our findings is given in the corresponding paragraphs (4.1, 4.2 and 4.3). Each of the paragraphs includes a description of representation issues linked with the approach and methods used, input, process and main outcome. Most of the case studies include elements that can be attributed to more than one cluster. As mentioned, the clusters are not a typology nor a comprehensive classification of the case studies. To better illustrate our finding, we did include for each of the paragraphs examples of good practice out of the case studies. In addition, implications for practitioners are highlighted by elaborating elements of good practice and areas of improvement.

\subsection{Window of opportunity}

Leveraging the first perspective, i.e. window of opportunity, we looked at scenarios as a tool to support planning and decision-making. Our analysis indicates contrasting motivations between developing and using future scenarios in the case studies from Appendix 1 . When the motivation is oriented towards developing scenarios, the focus tends to shift towards building consensus within the scenarios, missing the opportunity to explore the potential for innovation in conflicting views. Although legitimate for several reasons, for example building a common platform for dialogue, a focus on consensus can take up too much resources (Borch \& Mérida, in press), with a risk of diluting a sense of urgency. In addition, our analysis indicates that scenarios with a strong focus on consensus during the development are often too vague and too broad for defining tangible innovation opportunities. By reshaping the scenarios to reach consensus, they 
are often limited to accepted statements about the obvious. Some examples of national foresights based on Delphi are known to have experienced problems linked with a dominance of consensus, see for instance Göll (in press).

This is in contrast with scenario exercises, where the motivation is oriented towards using the future scenarios for strategic discussions. The focus here is less on which scenarios are "right" but is more oriented to whether the scenarios delineate the range of possible futures appropriately (Geyer \& Scapolo, 2004). As documented by van der Heijden (1996), the strategic discussion has its origin in uncertainty, both in the external environment and within the organisation. Using inspirational scenarios (in this context, one could label them as simple in form but representing extreme uncertainties) can contribute strongly to triggering feelings of surprise and discovery. Responding to this emotive and cognitive disruption requires participants (i.e. users) to think in ways that produce innovative and competitive solutions in a changing environment. The DP21 scenarios (see Appendix 1) are a good example. As an implication for practitioners, we recommend that careful design of scenario exercises is needed to achieve a balance between developing and using scenarios to strengthen the sense of urgency.

\section{2 Legitimacy for action}

Looking at the second perspective, i.e. legitimacy for action, our analysis revealed three clusters in the case studies from Appendix 1. The following paragraphs will describe the main characteristics for each of the clusters (resp. 4.2.1 framing boundaries, 4.2.2 back-casting from targets and 4.2 .3 back-casting from principles).

\subsubsection{Framing boundaries}

A first cluster is characterised by a focus on framing boundaries. The "Prelude Scenarios" 3 are a good example (see Appendix 1). An important input for the scenario work in this cluster are the comprehensive descriptions of the external drivers for change highlighting the uncertainty of future developments. This uncertainty is reflected in a distinguished set of possible long-term future images that are often derived from a multi-axes framework of the most important but uncertain drivers of change. Scenarios generated using the axes' process are explorative rather than normative; they tend to focus on the strategic level although additional layers of detail can subsequently be added. The value of the set of scenarios lays in the capacity to explore boundaries. This method is excellent for presenting a rich picture of multiple facets of a potential future: when an experienced scenario writer or film-maker is engaged at the final stage, the set of scenarios produced can be very persuasive, even to a non-specialist audience. Narratives are a natural, resonating way for people to communicate, and can be helpful in dealing with complexity, as pointed out by Weick (1995). These narratives can create shared meanings and by doing so they legitimate the future since imaginations are owned by the individuals relating them (Inayatullah, 1990). Creating awareness for the unforeseen is most often an important objective and desired outcome of this cluster of scenario exercises.

A technique underpinning these types of scenarios is described by Weiner \& Brown (2006) as the extremes that inform the middle. We found that adapting for change is often the general theme in the lessons-learned. Still, it is less obvious how these scenarios can be used for bridging today's decisions with the future images. We found that crystallising concrete policy initiatives for innovation from long-term future images, i.e. beyond twenty years, can be difficult. Most often, the scenarios are used to highlight important societal assets under threat. This links

\footnotetext{
${ }^{3}$ PRELUDE: PRospective Environmental analysis of Land Use Development in Europe, EEA (2006)
} 
well with the concept of risk-society (Beck, 1995) and risk management. Our analysis suggests that this can be partly contributed to the selected process design for developing the scenarios. By having a strong focus on the external dimension, adapting for change is logically seen as the dominant response. In that sense the potential for innovation within the system is less acknowledged.

When considered from the perspective of creating legitimacy for action we also suggest that the scenarios in this cluster could benefit from complementary techniques connecting the long-term future images to the present via stepping stones. Using roadmaps is an example of such a complementary technique for linking scenarios with internal innovation capabilities. This would help to address the imbalance between outward and inward reflection. Moreover, while participatory scenario-making provides visions for multiple futures, a roadmap only operates with one vision. Linking scenarios with technology roadmapping initiates an exploratory and creative phase to identify and understand uncertainties. Developing a set of scenarios acknowledges multiple rather than one future, equally plausible, whereas roadmapping provides a framework for condensing all information in one map and timeframe - revealing windows of opportunity thus linking decision-making with future scenarios. The legitimising aspect of this is the creation of a common understanding of challenges and establishing a common vision amongst the innovation stakeholders as a boundary framework before moving into technology roadmapping (Ricard and Borch, 2011).

\subsubsection{Back-casting from targets}

A second cluster is characterised by a focus on back-casting from targets. "Getting into the Right Lane for 2050" ${ }^{4}$ and $A G 2020^{5}$ are good examples here (see Appendix 1). In this cluster, changes in the external environment are part of the scenarios. But in contrast with the first cluster, change is less described by framing very different long-term future worlds. The focus of the scenarios in the second cluster is oriented rather towards a sequence of clear targets linked with short-term step-stones, i.e. 5-10 year. By breaking up the long-term in more tangible time periods it helps to understand the necessary steps for embracing change. By mapping time, we become clearer on where we have come from and where we are going. This 'roadmap' linking the necessary steps, contributes to the recognition that the long-term target is not only possible but also achievable. In addition, the interplay of the different contributions to achieve the targets becomes more visible. The foreseen outcome of long-term investments or policies, for example, can be visualised and confronted with a changing environment. Different from the above cluster, this one already leverages the combined use of roadmaps. We found that selecting areas for future opportunities are the general theme in the lessons-learned from this cluster. Often the focus is very much on elaborating areas of enhanced institutional collaboration, technological cooperation and converging technologies. Clearly innovation is an essential feature of the scenarios. The images of the future are focused on key internal developments and often technology driven or driven by changes in our way of living.

Our analysis also suggests possible improvements for this cluster. Roadmaps directed towards a single target are likely to be inappropriate where policy intervention may direct technology towards a different trajectory altogether (Saritas \& Aylen, 2010; Ricard and Borch, 2011). The innovation potential of the scenarios can be strengthened through broadening the system boundaries and enriching the future images. Flexibility, either avoidance of surprises or fast utilization of sudden opportunities, becomes one of the key issues. In order to avoid surprises

\footnotetext{
${ }_{5}^{4}$ PBL \& Stockholm Resilience Centre (2009)

${ }^{5}$ AG2020 Foresight analysis for world agricultural markets (2020) and Europe. DG RTD (2011)
} 
the policy/strategy process should be able to open the scope of observation for periphery incidents and early, unstructured data that implicate potential discontinuities (IImola \& Kuusi, 2006). In addition, including perspectives from the different stakeholders can reveal new areas for innovation (Prell et al., 2007).

\subsubsection{Back-casting from principles}

A third cluster is characterised by a focus on back-casting from principles. A good example can be found with the scenario practice developed by the Natural Step ${ }^{6}$ (see for instance Givaudan, 2011 in Appendix 1). The main focal points of the scenarios are sustainability concerns and criteria. The principles can be seen as indirect and implicit representations of the future. The future plays the role of the time needed to introduce the necessary changes to comply with the envisaged principles. Change is implicit part of the scenarios but the focus is less on delineating the range of possible futures. Interaction between the organisation and the environment is seen as the main driver. This is often reflected in the outcomes envisioning a preferable future and experiments towards that future.

Also for the third cluster, we suggest some areas of improvement with regard to legitimising actions by adding a planning perspective via roadmaps or similar approaches. Comprehensive and well-designed roadmaps linking today's experiments with future images can improve the impact of the scenarios. In addition the success of the roadmaps can be tested for different possible future images. This will provide essential information about the robustness of the innovation potential.

The $3^{\text {rd }}$ SCAR foresight exercise (EC, 2011b, see Appendix 1 ) also falls into this cluster with its focus on research priorities and innovation to meet necessary change and uncertainties in the agri-food sector facing resource constrains and environmental limits. In the project report, the impacts of the scenarios are implemented as research priorities, but the implementation could be improved with regards to knowledge dissemination e.g. education and the scientific societies involvement in policy discourse.

\subsection{Empowering stakeholders}

Developing and using future scenarios to inspire innovation does not only deal with the collection of data and models; it also involves the interaction of the stakeholders, their ideas, values and capacities for social change. Looking at the third perspective, i.e. empowering stakeholders. Our analysis of the case studies from Appendix 1 revealed two clusters: i.e. expert versus stakeholder driven.

In the past decades, expert judgement was the main input for scenario development. Involvement of stakeholders was not intentionally looked for. The Delphi-technique for instance is a forecasting technique that uses estimates from mainly experts (Rowe \& Wright, 2001). In reality, this might lead to limitations. Firstly, the expert (i.e. scientific) mind-set fosters expectations of regularity, simplicity and certainty in the phenomena and in our interventions (Funtowicz \& Ravetz, 1993). But these can inhibit the understanding of the problems and of appropriate methods to their solution (van't Klooster \& van Asselt, 2011). Secondly, whilst

\footnotetext{
${ }^{6}$ http://www.naturalstep.org/
} 
expertise has never been either as widespread or in such demand as today, public willingness to challenge that expertise has also never been as high. As a result, the boundary between experts and the wider public has become blurred whenever one speaks of users and producers of knowledge (Nowotny, 2003).

Our analysis suggests that scenarios developed with broader stakeholder/expert participation will provide richer future images that go beyond the probable that is determined by the past and present (Prell et al., 2007, Jetter \& Schweinfort, 2011). As opposed to past scenario practice, we believe there is often no clear cut difference between experts and stakeholders: experts sometimes have a stake in the problem or solution discussed and stakeholders equally have their expertise. It is a key challenge to benefit from this rich and complex audience.

Also from this 'empowerment' perspective we suggest some areas of improvement. Stakeholder involvement, for instance, may be facilitated by conceptualising the future as open and dilemmatic, and recognizing ambivalence as legitimate (Höijer et al., 2006). Thus the scenario process can be seen as frame for dialogue, not to reach consensus but to recognize other parties' point of view. Recognition then, is a heuristic that leads away from conflict into a broader understanding of the complexity of a disputed subject (Borch \& Mérida, in press). Although consensus can identify common grounds in contested territory, it should not be the primary goal of scenario processes. Rather we suggest that developing and using scenarios should be viewed as a systemised negotiation process among key stakeholders (social actors), investigating and utilizing potential future societal changes and developments (see also De Smedt, 2007 and Borch \& Mérida, ibid.).

To synthesise this section on results and implications, we argue that our reflexive inquiry of the selected cases from Appendix 1 helped to disclose several representation issues in scenario practice. Using a policy perspective, different clusters of practice have been revealed. In the next section we will discuss our findings against the initial key question of how futures thinking and scenarios can help to better cope with the grand challenges and how future scenarios can inspire innovation.

\section{Discussion}

Due to the social dynamic characteristic of innovation, new socio-technical subsystems are emerging (Carlsson et al., 2002), however following a policy perspective, there is lack of exploitation of innovative solutions for orienting innovation in itself along more sustainable pathways (OECD, 2011). For instance, there is a wide acceptance that the disconnection between economic growth and well-being is increasing. At the same time innovation has become one of the main engines of growth. However, these two overarching trends have not yet been reconciled (OECD, 2011). In this paper we argue that issues of representation have played a part in this lack of exploitation. For example, when drivers of change are not only multiple but also mutable, it is not sensible to extrapolate the future from data and relationships of the past. Hence, it is important to recognise that representing scientific and technological diversity offers an important mean to help foster more effective forms of innovation and promote social learning (Stirling, 2007). This complexity challenges the capacity of innovation systems to acknowledge the social dimension of innovation and to learn from experience.

In both science and policy, it is accepted that visions about the future is an essential element of a strategy (for instance EC, 2011a., Hamel \& Prahalad, 1994). In addition, several scholars state that scenarios constitute a major tool for considering the future in strategic planning (Porter, 1985, Bradfield et al., 2005, Ringland, 2010). The question that emerges is how we can learn 
from using and developing future scenarios to assist in the orientation of innovation systems? Developing and using scenarios can be considered a field of applied research, i.e. where particular methods are applied to 'solve' particular puzzles. Particular choices and uses of techniques will be influenced by the context in which applications are made. Contextual features will include, amongst other things, the morphology or physiology of the domain, the purpose and theoretical premises of the study, the community of practice being informed and the values inherent in the process. In this sense, no single discipline or particular prescribed set of methods can be considered to be optimal. However, the commonality of scenario applications is the orientation to the future and that the knowledge produced is uncertain. Therefore, being a professional practice to support significant decisions, developing and using scenarios needs to be more assured of its claims to knowledge (Fuller \& De Smedt, 2008).

Following a reflexive inquiry methodology (Alvesson \& Sköldberg, 2000; Cunliff, 2003; see section 2 material and methods) in the analysis of the scenario cases listed in Appendix 1, three complementary questions on policy change are applied to analyse scenario practice: (i) "How can developing and using future scenarios present a window of opportunity to effectively drive decisions?"; (ii) "How can developing and using future scenarios enhance the legitimacy for action?"; and (iii) "How can developing and using future scenarios provide evidence to decisionmakers empowering the stakeholders involved?". By questioning representation from a policy perspective and deconstructing future scenario practice, we were able to (re)construct findings to the above questions: (i) if a sense of urgency was established or was lacking (window of opportunity), (ii) what was and was not represented (legitimacy for action) and (iii) who was and who was not involved (empowering stakeholders). An overview of our findings is presented in Table 2. This table links issues of representation with clusters of practice.

Based on our findings of the analysis of scenario practice in the case studies of Appendix 1 , Table 2 describes for each cluster of practice (see Section 4.1, 4.2 and 4.3) the most common used images of the future, an example of a characteristic technique and the dominant mode of futures thinking.

Table 2: Clusters of future scenario practice from a policy perspective

\begin{tabular}{|c|c|c|c|c|}
\hline (policy perspective) & $\begin{array}{c}\text { Scenario } \\
\text { Practice } \\
\text { (most characteristic) }\end{array}$ & $\begin{array}{l}\text { Types of futures } \\
\text { in focus } \\
\text { (most characteristic) }\end{array}$ & (example) & $\begin{array}{l}\text { Modes of futures } \\
\text { thinking } \\
\text { (most characteristic) }\end{array}$ \\
\hline \multirow{2}{*}{$\begin{array}{l}\text { Window of } \\
\text { opportunity } \\
\text { (yes/no sense of } \\
\text { urgency) }\end{array}$} & Using scenarios & $\begin{array}{l}\text { Shaped by surprise } \\
\text { and confrontation }\end{array}$ & $\begin{array}{l}\text { Uncertainty } \\
\text { matrix }\end{array}$ & Intuitive \\
\hline & $\begin{array}{l}\text { Developing } \\
\text { scenarios }\end{array}$ & $\begin{array}{l}\text { Shaped by } \\
\text { convention }\end{array}$ & $\begin{array}{l}\text { Consensus } \\
\text { (Delphi) }\end{array}$ & $\begin{array}{l}\text { Bounded } \\
\text { rationality }\end{array}$ \\
\hline \multirow{3}{*}{$\begin{array}{l}\text { Legitimacy for } \\
\text { action } \\
\text { (what is and is not } \\
\text { represented) }\end{array}$} & $\begin{array}{l}\text { Framing } \\
\text { boundaries }\end{array}$ & $\begin{array}{l}\text { Shaped by possible } \\
\text { futures }\end{array}$ & $\begin{array}{l}\text { Extreme to } \\
\text { inform the } \\
\text { middle }\end{array}$ & Eventuality \\
\hline & $\begin{array}{l}\text { Back-casting from } \\
\text { targets }\end{array}$ & $\begin{array}{l}\text { Shaped by } \\
\text { probable futures }\end{array}$ & S\&T Roadmaps & Predictive \\
\hline & $\begin{array}{l}\text { Back-casting from } \\
\text { principles }\end{array}$ & $\begin{array}{l}\text { Shaped by } \\
\text { preferable futures }\end{array}$ & The natural step & Visionary \\
\hline
\end{tabular}




\begin{tabular}{lcccc}
\hline & Expert driven & $\begin{array}{c}\text { Shaped by } \\
\text { expertise and } \\
\text { discovery }\end{array}$ & Expert panels & Technocratic \\
$\begin{array}{l}\text { Empowering } \\
\text { stakeholders } \\
\text { (who is and is not } \\
\text { represented) }\end{array}$ & $\begin{array}{c}\text { Stakeholder } \\
\text { driven }\end{array}$ & $\begin{array}{c}\text { Shaped by } \\
\text { interaction }\end{array}$ & $\begin{array}{c}\text { Future } \\
\text { workshops }\end{array}$ & Evolutionary \\
\hline
\end{tabular}

Table 2 is a synthesis of our results and implications of the previous section. Instead of framing practice based on theory, future scenario practice is deconstructed into seven clusters. In Table 2 these seven clusters are further linked to the most characteristic theoretical premises, here expressed as modes of futures thinking. For example, looking at 'window of opportunity', we argue that a strong focus on developing scenarios and consensus increases a risk of diluting a sense of urgency. During the scenario exercise, consensus may not be appropriate to promote differences and to stimulate novel ideas. Based on this observation (see Section 4.1), two clusters of practice can be distinguished: one cluster with using scenarios as the most characteristic feature, and another with developing scenarios as the most characteristic. For the two clusters, the scenario cases have been analysed to disclose elements of theoretical premises. In the first cluster, we found that the scenarios are used for supporting strategic discussions about futures that are shaped by surprise and confrontation. Examples of supportive techniques are the use of an uncertainty matrix and the multi-axes method using factors of highuncertainty and high impact. Based on our reflexive inquiry used to analyse scenario exercises in their context, we can then attribute the most characteristic mode of thinking ${ }^{7}$.

Table 3 provides a brief description for each of the 7 dominant modes of futures thinking. This table also includes for each of the modes of future thinking proposed effects on or contributions to the enablers and barriers for orientating innovation systems through future scenarios.

Table 3: Linking innovation systems with different modes of futures thinking

\begin{tabular}{cccc}
\hline $\begin{array}{c}\text { Modes of } \\
\text { futures } \\
\text { thinking }\end{array}$ & Leading theme & $\begin{array}{c}\text { Types of } \\
\text { futures in } \\
\text { focus }\end{array}$ & $\begin{array}{c}\text { Enablers and barriers for orienting } \\
\text { innovation systems }\end{array}$ \\
\hline Intuitive & $\begin{array}{c}\text { The aim is to think "the } \\
\text { unthinkable" and to } \\
\text { conceptualise future situations } \\
\text { where uncertainties are high }\end{array}$ & $\begin{array}{c}\text { Shaped by } \\
\text { surprise and } \\
\text { confrontation }\end{array}$ & $\begin{array}{c}\text { Allows strong imagination including } \\
\text { alternative futures that are competing } \\
\text { Weak on acceptance, especially by } \\
\text { decision-makers }\end{array}$ \\
\hline $\begin{array}{c}\text { Bounded } \\
\text { rationality }\end{array}$ & $\begin{array}{c}\text { The aim is to agree on } \\
\text { common accepted } \\
\text { probabilities of change } \\
\text { (rejecting extreme ideas) }\end{array}$ & $\begin{array}{c}\text { Shaped by } \\
\text { convention }\end{array}$ & $\begin{array}{c}\text { Strong on acceptance and alignment, but } \\
\text { often too vague, too broad to inspire } \\
\text { innovation }\end{array}$ \\
\hline Eventuality & $\begin{array}{c}\text { The aim is to explore } \\
\text { contrasting futures and to } \\
\text { conceptualise future situations }\end{array}$ & $\begin{array}{c}\text { Shaped by } \\
\text { possible futures }\end{array}$ & $\begin{array}{c}\text { Allows rigorously exploring boundaries } \\
\text { and complexity. Often an imbalance } \\
\text { between outward/inward reflection }\end{array}$ \\
\hline $\begin{array}{l}\text { The clusters are not (intended to be) a typology. In each of the cases elements and aspects of different clusters are } \\
\text { present, therefore it is not possible to link clusters with cases. However, as described in the previous section, for each } \\
\text { of the clusters an example(s) of good practice is included. }\end{array}$
\end{tabular}




\begin{tabular}{|c|c|c|c|}
\hline & $\begin{array}{c}\text { for the long-term where } \\
\text { uncertainties are expressed } \\
\text { differently }\end{array}$ & & $\begin{array}{l}\text { limiting the recognition of its internal } \\
\text { innovation capacity }\end{array}$ \\
\hline \multirow[t]{2}{*}{ Predictive } & \multirow{2}{*}{$\begin{array}{l}\text { The aim is to be better } \\
\text { contextualize what we know to } \\
\text { be prepared handling } \\
\text { upcoming situations }\end{array}$} & \multirow[t]{2}{*}{$\begin{array}{l}\text { Shaped by } \\
\text { probable futures }\end{array}$} & $\begin{array}{l}\text { Allows defining (a sequence of ) clear } \\
\text { steps for innovation. }\end{array}$ \\
\hline & & & Weak on surprise and external change \\
\hline \multirow[t]{2}{*}{ Visionary } & \multirow{2}{*}{$\begin{array}{l}\text { The aim is to envision how } \\
\text { society can be designed in a } \\
\text { better (more sustainable way) }\end{array}$} & \multirow{2}{*}{$\begin{array}{l}\text { Shaped by } \\
\text { preferable } \\
\text { futures }\end{array}$} & $\begin{array}{l}\text { Allows creating authentic alternative } \\
\text { visions to guide innovation. }\end{array}$ \\
\hline & & & $\begin{array}{c}\text { Weak on clear targets, surprise and } \\
\text { external change }\end{array}$ \\
\hline \multirow[t]{2}{*}{ Technocratic } & \multirow{2}{*}{$\begin{array}{c}\text { The aim is to demonstrate } \\
\text { technical feasibility and } \\
\text { optimise technological } \\
\text { development }\end{array}$} & \multirow{2}{*}{$\begin{array}{l}\text { Shaped by } \\
\text { expertise and } \\
\text { discovery }\end{array}$} & $\begin{array}{l}\text { Allows minimising inconsistencies and } \\
\text { defining areas for innovation }\end{array}$ \\
\hline & & & $\begin{array}{l}\text { Weak on complexity of socio- } \\
\text { technological systems }\end{array}$ \\
\hline \multirow[t]{2}{*}{ Evolutionary } & \multirow{2}{*}{$\begin{array}{l}\text { The aim is to engage in } \\
\text { sustainable pathways } \\
\text { enabling transformations of } \\
\text { innovation systems }\end{array}$} & \multirow[t]{2}{*}{$\begin{array}{l}\text { Shaped by } \\
\text { interaction }\end{array}$} & $\begin{array}{l}\text { Allows a systemised negotiation process } \\
\text { linking a variety of social actors and } \\
\text { creating the conditions for innovation }\end{array}$ \\
\hline & & & $\begin{array}{l}\text { Risk of not reaching out to key } \\
\text { (technological) actors }\end{array}$ \\
\hline
\end{tabular}

Innovation is not only about invention, creation, or discovery, it is also about adaptation and emergence of new innovation systems (Coates, 2003). Principles on how to orient innovation systems through future scenarios will require conditions for collaboration. The solutions developed should not simply be based in an academic research unit, in the company research and development department, or in the policy think tank. They should be socially reflexive and negotiated by the key actors (Goodwin, 2011). However, it is also crucial to keep in mind the limitations of the scenario methodology (Godet, 2000). Clearly, scenarios do not point to simple short-cuts into a more sustainable future (Geyer \& Scapolo, 2004).

Firstly, our analysis of the case studies from Appendix 1, suggests that a variety of modes of futures thinking, as articulations of theoretical premises, can be distinguished in future scenario practice. Secondly, our analysis abstracted different dominant modes of futures thinking linked within different clusters. In reality, each scenario exercise is a mixture of different modes and practice is shaped by the image(s) of the future and the techniques applied. Combinations of techniques are possible and found in our case studies and in literature (see for instance Postma \& Liebl, 2005 and Saritas \& Aylen, 2010). However to strengthen the enablers for innovation, the link between practice and theory, represented via the modes of futures thinking should be acknowledged when designing and implementing future scenario exercises. As described in Section 4 (results and implications) cross-fertilisations between the techniques of the different clusters can enhance the innovation potential. However, no single recipe exists and our recommendations should be seen as 'design principles'. Hence, the benefits from combining techniques for each of the clusters become also clear from a theoretical point of view when looking at combination possibilities of the modes of futures thinking in Table 3.

To synthesise, we argue that future scenarios developed with a combination of well-designed modes of futures thinking will provide richer future images that go beyond the probable that is determined by the past and present. This enhanced support is needed, because as Hauschildt 
(2003) clearly states: "the success of innovation is to a great extent dependent upon the activities and abilities of individuals who enthusiastically support it".

\section{Conclusions}

In this paper we analysed and discussed the applicability of future scenarios as narratives to represent and discuss different perspectives on past, present and future developments. Our use of a reflexive methodological approach with three complementary questions on policy change supported the clustering of different approaches of developing and using future scenarios as a tool for orienting innovation systems. Our analyses of the scenario case studies from Appendix 1 revealed elements of good practice and implications on how better to address innovation through future scenarios. For instance, different modes of futures thinking have been identified through the process of deconstruction. In this paper, we argue that these modes of futures thinking are shown to contribute in different ways to orientating innovation systems. Hence, by using a reflexive methodology we were able to create a powerful heuristic to challenge current scenario practice and to learn from experience. In addition, we also identified some points of departure for further refinement.

Firstly, and summarising our recommendations for future scenario practice, we suggest that representation issues (i.e. what is, and what is not represented in the scenarios, who was and who was not involved, and whether a sense of urgency was established or was lacking) are an important feature in the design and application of future scenario practice. In this paper we argue that the limits of current practice are to a certain extent linked with representation issues. As acknowledged in the previous sections (see also Table 2 and 3), cross-fertilisation between scenario approaches and techniques, such as framing boundaries, roadmapping, and backcasting from principles can strongly enhance practice by enhancing representation. We also want to acknowledge the limits of our analysis: i.e. using a policy perspective for doing an expost analysis of future scenario practice. Innovation systems are complex and dynamic and scenario practice is applied more widely than our sample. Also, other analytical perspectives exist and may be equally valid (Cunliffe, 2003), see for instance Seidl \& van Aaken (2009). Therefore, when using reflexivity in research or in scenario practice, it is also essential to make one's perspective clear so that the claims to knowledge can be constructively critiqued and improved.

Secondly, we argue that the use of cooperative strategies, i.e. participatory scenario analysis, is required to produce a variety of possible, and not only probable or desired futures among the actors that develop, diffuse, and use innovations. Hence, we believe that developing and using scenarios should be viewed as a systemised negotiation process among key stakeholders (social actors), investigating and utilizing potential future societal changes and developments. This integrated approach, i.e. integrating different modes of futures thinking, is needed for orienting innovation along more sustainable pathways enabling transformations of sociotechnical systems. However, a variety of representation issues exist, and more experiments and research are needed.

Thirdly, we want to emphasise that the social dimension in innovation systems should be acknowledged as a legitimate research area and linkages with social innovators and other social innovation stakeholders should be strengthened so that social innovation experiments inform the 
research community. Innovation systems, described by Edquist (2007) as networks of actors and institutions that develop, diffuse and use innovations, are essential for addressing the grand challenges.

\section{Acknowledgements}

The authors are grateful to the COST Action A22 network, IPTS and different past and present foresight network initiatives such as the European Foresight Platform and ForLearn for organising creative discussion platforms on foresight and scenario initiatives. The constructive comments of the anonymous reviewers were very helpful to better focus and shape this paper.

\section{References}

M. Aaltonen, Multi-ontology, sense-making and the emergence of the future, Futures 41 (2009) 279283.

B. Adam, Futures Transformed, 2006. Last accessed on 31/001/12 and available at http://www.cardiff.ac.uk./socsi/futures/wp ba futurestransformed231006.pdf

M. Alvesson, K.Sköldberg, Reflexive methodology: New vistas for qualitative research towards a reflexive methodology, London: Sage, 2000.

P.D. Andersen, M. Borup, K. Borch, J. Kaivo-oja, A. Eerola, T. Finnfjörnsson, E. Øverland, E.A Eriksson, T. Malmér, B.A. Mölleryd, Foresight in Nordic innovation systems, Oslo, Nordic Innovation Centre, 2007.

U. Beck, Ecological Politics in an Age of Risk, Cambridge: Polity Press, 1995.

H.S. Becker, Scenarios: A Tool of Growing Importance to Policy Analysts in Government and Industry, Technology Forecasting and Social Change 23 (1983) 95120.

P.J. Beers, A. Veldkamp, F. Hermans, D. van Apeldoorn, J.M. Vervoort, K. Kok, Future sustainability and images, Futures 42 (2010) 723732.

M. Boden, C.Cagnin, V. Carabias, K. Haegeman, T. Konnola, Facing the future: time for the EU to meet global challenges, Luxembourg, Publications Office of the European Union, EUR 24364 EN, 2010. http://ftp.jrc.es/EURdoc/JRC55981.pdf

K. Borch, F. Mérida, Dialogue in Foresight: Consensus and Negotiation, In: K. Borch, S.M. Dingli, M.S. Jorgensen (Eds.), Exploring the Future. The Role of Interaction in Foresight. Cheltenham: Edward Elgar, (in press).

L. Borjesön, M. Hojer, K-H. Dreborg, T. Ekvall, G. Finnveden, Scenario types and techniques: towards a user's guide, Futures 38 (2006) 723739.

R. Bradfield, G. Wright, G. Burt, G.Cairns, K. Van Der Heijden, The origins and evolution of scenario techniques in long range business planning, Futures 37 (2005) 795812.

C. Cagnin, E. Amanatidou, M. Keenan, Orienting innovation systems towards grand challenges and the roles that FTA can play, Proceedings of the Fourth International Seville Conference on Future-Oriented Technology Analysis (FTA), FTA for structural and systemic transformations in response to grand societal challenges: integrating insights, transforming institutions and shaping innovation systems, Seville, 12-13 May, 2011. 
B. Carlsson, R. Stankiewicz, On the nature, function, and composition of technological systems, Journal of Evolutionary Economics 1 (1991) 93118.

B. Carlsson, S. Jacobsson, M. Holmén, A. Rickne, Innovation systems: analytical and methodological issues, Research Policy 31 (2002) 233245.

T.J. Chermack, Studying Scenario Planning: Theory Research Suggestions, and Hypotheses, Technological Forecasting and Social Change 72 (2005) 5973.

J.F. Coates, Future innovations in science and technology, In: L.V. Shavinina (Ed.): The International Handbook on Innovation, London: Pergamon, 2003. ISBN: 978-0-08-044198-6

A.L. Cunliffe, Reflexive inquiry in organizational research: questions and possibilities, Human Relations 56 (2003) 9831003.

O. Da Costa, P. Warnke, C. Cagnin, F. Scapolo, The impact of foresight on policy-making: Insights from the FORLEARN mutual learning process, Technology Analysis and Strategic Management, 20 (2008) 369387.

P. De Smedt, Interactions between foresight and decision-making, Proceedings of the Second International Seville Seminar on Future-Oriented Technology Analysis: Impact of FTA Approaches on Policy and Decision-Making, Seville, 28-29 September, 2006.

P. De Smedt, Can Negotiating the future influence policy and social change? Paper presented at the Future seminar of the Centre for Technology, Innovation and Culture, University of Oslo, 7th of June, 2007.

K.H. Dreborg, Scenarios and Structural Uncertainty. Explorations in the Field of Sustainable Transport,. Doctoral Thesis, Stockholm: KTH Infrastructure, 2004.

EC, 2011a, Innovation Union Competitiveness report 2011, (Executive Summary). European Commission, DG Research and Innovation Brussels.

EC, 2011b, Sustainable food consumption and production in a resource-constrained world. 3rd Foresight Exercise. European Commission DG Research and Innovation, Directorate E Unit E.4, Brussels.

C. Edguist (Ed.), System of Innovation: Technologies, Institutions and Organizations, London: Pinter publishers, 1997.

C. Freeman, The national system of innovation in historical perspective, Cambridge Journal of Economics 19 (1995) 524.

T. Fuller, P. De Smedt, D. Rothman, Advancing foresight methodology through networked conversation. Proceedings of the Second International Seville Seminar on Future-Oriented Technology Analysis: Impact of FTA Approaches on Policy and Decision-Making - Seville 28-29 September, 2006.

T. Fuller, P. De Smedt, From oracles to dialogue, Proceedings of the Third International Seville Seminar on Future-Oriented Technology Analysis: Impacts and implications for policy and decision-making - Seville 16-17 October, 2008.

S. Funtowicz, J. Ravetz, Science for the Post-Normal Age, Futures, 25 (1993) 735755.

J.P. Gavigan, F. Scapolo, A comparison of national foresight exercises, Foresight 1 (1999) 495 517.

L. Georghiou, M. Keenan, J. Cassingena, I. Miles, R. Popper, The handbook of technology foresight: concepts and practice, Edward Elgar Publishing, 2008. 
A. Geyer, F. Scapolo, European manufacturing in transition - The challenge of sustainable development: Four scenarios 2015-2020, Innovation: Management, Policy \& Practice 6 (2004) 331343.

M. Godet, Integration of Scenarios and Strategic Management: Using Relevant, Consistent, and Likely Scenario, Futures, 22 (1990) 730739.

M. Godet, The Art of Scenarios and Strategic Planning: Tools and Pitfalls, Technological Forecasting and Social Change, 65 (2000) 322.

P. Goodwin, Spanning boundaries: social innovation in a complex world. In OECD (Ed.) Fostering innovation to address social challenges, Workshop proceedings, OECD, Paris, 2011, p. 5964.

T.J. Gordon, S\&T Roadmapping. In .J.C. Glenn, T.J. Gordon (Eds.), Futures Research Methodology. Version 2.0 AC/UNU Millennium Project, American Council for the United Nations University Washington D.C., US, 2003.

S.C.H. Greeuw, M.B.A. van Asselt, J. Grosskurth, C.A.M.H. Storms, N. Rijkens-Klomp, D.S. Rothman, J. Rotmans, Cloudy Crystal balls. An assessment of recent European and global scenario studies and models, Experts' corner report: Prospects and scenarios 4, European Environment Agency (EEA), Copenhagen, Denmark, 2000.

L. Gunderson, C. Folke, M. A. Janssen, Reflective practice, Ecology and Society 12(2007): 40. [online] URL: http://www.ecologyandsociety.org/vol12/iss2/art40/

G. Hamel, C.K. Prahalad, Competing for the Future, Boston: Harvard Business School Press, 1994.

C. Harries, Correspondence to what? Coherence to what? What is good scenario-based decision making? Technological Forecasting and Social Change 70 (2003) 797817.

J. Hauschildt, Promoters and champions in innovations: Development of a research paradigm, In L. V. Shavinina (Ed.), The international handbook on innovation (pp. 804- 811). London, UK: Pergamon, 2003.

M.P. Hekkert, R.A.A. Suurs, S.O. Negro, S. Kuhlmann, R.E.H.M. Smits, Functions of Innovation systems: A new approach for analysing technological change, Technological Forecasting and Social Change 74 (2007) 413432.

B. Höijer, R. Lidskog, Y. Uggla, Facing dilemmas: sense-making and decision-making in late modernity, Futures, 38 (2006) 350366.

L. Ilmola, O. Kuusi, Filters of weak signals hinder foresight: Monitoring weak signals efficiently in corporate decision-making, Futures 38 (2006) 908924.

S. Inayatullah, Deconstructing and reconstructing the future: predictive, cultural and critical epistemologies, Futures 22 (1990) 115141.

A. Jetter, W. Schweinfort, Building scenarios with fuzzy cognitive maps: an exploratory study of solar energy, (2011) Futures 43 (2011) 5266.

M.S. Jørgensen, Visions and visioning in foresight activities, In: K. Borch, S.M. Dingli, M.S. Jorgensen (Eds.), Exploring the Future. The Role of Interaction in Foresight, Cheltenham: Edward Elgar, (in press).

H. Lawson, Reflexivity. The post-modern predicament. La Salle, IL: Open Court, 1985.

C. Leadbeater, We-Think: The Power of Mass Creativity, Profile Books, London, 2008. 
M. Lindgren and $\mathrm{H}$. Bandhold Scenario planning: The link between future and strategy, Palgrave Macmillan, New York, 2003.

H. Linstone, On Discounting the Future, Technological Forecasting and Social Change 4 (1973) 335338.

H. Linstone, M. Turoff (Ed.), The Delphi Method, 2002. Last accessed 31/01/12 and available at http://www.is.njit.edu/pubs/delphibook

A. Lovins, Soft energy paths: towards a durable peace san Francisco, Friends of the Earth International, 1977, 231p.

B.A. Lundvall, (Ed.) National Systems of Innovation: Towards a Theory of Innovation and Interactive Learning, London, Pinter, 1992.

A. Marchais-Roubelat, F. Roubelat, Futures beyond disruptions, Futures 43 (2011) 130133.

L.K. Mytelka, K. Smith, Policy learning and innovation theory: an interactive and co-evolving process, Research Policy 14 (2002) 113.

R. Nelson, S. Winter, In search of a useful theory of Innovation, Research Policy 6 (1977) 3676.

H. Nowotny, Democratising expertise and socially robust knowledge, Science and Public Policy 30 (2003) 151156.

OECD, Fostering innovation to address social challenges, Workshop proceedings, OECD, Paris, 2011.

R. Phaal, C. Farrukh, D. Probert, T-plan. The fast start to technology roadmapping. Planning your route to success, Centre for Technology Management, IfM University of Cambridge, 2001.

T.J.B.M. Postma, F. Liebl, How to improve scenario analysis as a strategic management tool, Technological Forecasting and Social Change 72 (2005) 161173.

M.E. Porter, Competitive Advantage, Free Press, New York, 1985.

C, Prell, .K. Hubacek, M.S. Reed, C. Quinn, N. Jin, J. Holden, T.P. Burt, M. Kirby, J. Sendzimir, If you have a hammer everything looks like a nail: traditional versus participatory model building, Interdisciplinary Science Reviews 32 (2007) 120.

L.M. Ricard, K. Borch, From Future Scenarios to Roadmapping: Guiding Exploratory Innovation and Strategy. The 4th International Seville Conference on Future-Oriented Technology Analysis (FTA): 12 \& 13 May, 2011.

T. Rickards, The future of innovation research, In: L.V. Shavinina (Ed.): The International Handbook on Innovation, London, Pergamon, 2003. ISBN: 978-0-08-044198-6

G. Ringland The role of scenarios in strategic foresight, Technological Forecasting and Social Change77 (2010) 14931498

J. Rotmans, M.B.A. van Asselt, C. Anastasi, S. Greeuw, J. Mellors, S. Peters, D. Rothman, N. Rijkens, Visions for a sustainable Europe, Futures 32 (2000) 809831.

G. Rowe, G. Wright, Expert Opinions in Forecasting. Role of the Delphi Technique, In: J.S. Armstrong (Ed.): Principles of Forecasting: A Handbook of Researchers and Practitioners, Boston: Kluwer Academic Publishers, 2001.

O. Saritas, J. Aylen, Using scenarios for roadmapping: The case of clean production, Technological Forecasting \& Social Change 77 (2010) 10611075. 
P.J.H. Schoemaker, Scenario Planning: A Tool for Strategic Thinking, Sloan Management Review (1995) 2540.

D. Seidl, D. van Aaken, Anticipating critique and occasional reason: modes of reasoning in the face of a radically open future", in: L. Costanzo, B. MacKay (Eds.), The handbook of research on strategy and foresight, Cheltenham: Edward Elgar, pp. 48-65.

C. Selin, Time Matters: Temporal Harmony and Dissonance in Nanotechnology Networks, Time and Society 15 (2006) 121139.

R. Sternberg, J. Pretz, J. Kaufman, Types of innovation, In L. V. Shavinina (Ed.), The international handbook on innovation (pp. 158-169), London, UK: Pergamon, 2003.

A. Stirling, A general framework for analysing diversity in science, technology and society, Journal of the Royal Society Interface 4 (2007) 707719.

A. Timmermans, Arenas as Institutional Sites for Policymaking: Patterns and Effects in Comparative Perspective, Journal of Comparative Policy Analysis: Research and Practice 3 (2001) 311337.

K. van der Heijden, Scenarios: The Art of Strategic Conversation, Wiley, Chichester, 1996.

S.A. van' t Klooster, M.B.A. van Asselt, Accommodating or compromising change? A story about ambitions and historic deterministic scenarios, Futures 43 (2011) 8698.

P.W.F. van Notten, J.Rotmans, M.B.A., van Asselt, D.S. Rothman, An updated scenario typology, Futures 35 (2003) 423443.

T. Webler, D. Levine, H. Rakel, D. Renn, A novel approach to reducing uncertainty the group Delphi, Technological Forecasting and Social Change 39 (1991) 253263.

A. Webster, Technologies in transition, policies in transition: foresight in the risk society, Technovation 19 (1999) 413421.

K. Weick, Sensemaking in Organizations, Sage, London, 1995.

E. Weiner, A. Brown, Future Think: How to Think Clearly in a Time of Change. Pearson, Prentice Hall, New York, 2006.

A. Wilkinson, E. Eidinow, Evolving practices in environmental scenarios: a new scenario typology. Environ. Res. Lett. 3 (2008).

I. Wilson, From Scenario Thinking to Strategic Action. Technological Forecasting and Social Change 65 (2000) 2329.

E. Wollenberg, D. Edmunds, L. Buck, Using scenarios to make decisions about the future: anticipatory learning for the adaptive co-management of community forests, Landscape and Urban Planning 47 (2000) 6577. 


\section{Appendix 1. Overview of the case studies}

1. AG2020 Foresight analysis for world agricultural markets (2020) and Europe. DG RTD (2011), www.ag2020.org

2. K. Borch, (in press) The Danish Technology Foresight on Environmentally Friendly Agriculture. In Exploring the future The role of interaction in foresight. Borch et al., (Eds.) Edward Elgar Cheltenham, UK.

3. DP21 (2003) Dierlijke Productie \& Consumptie in de 21ste eeuw. Last accessed on 29/06/11 and available in Dutch at http://www.kbs-frb.be/uploadedFiles/KBSFRB/Files/NL/PUB 1338 DP21 Stakeholders.pdf

4. Duwobo (2010) Transitiemanagement duurzaam wonen en bouwen. Last accessed on 29/06/11 and available in Dutch at http://www. duwobo.be/index.cfm

5. EC (2008) New challenges for agricultural research: climate change, food security, rural development, agricultural knowledge systems. The 2nd SCAR Foresight Exercise. Last accessed on 29/06/11 and available at http://ec.europa.eu/research/agriculture/scar/pdf/scar 2nd foresight exercise en.pdf

6. EC (2011b) Sustainable food consumption and production in a resource-constrained world. 3rd Foresight Exercise. European Commission DG RTD, Directorate E Unit E.4, Brussel.

7. EEA (2006) Prelude (PRospective Environmental analysis of Land Use Development in Europe) scenarios. Available at http://www.eea.europa.eu/multimedia/interactive/prelude-scenarios/prelude

8. European Commission (2009) The world in 2025. Rising Asia and socio-ecological transition. Research*eu, Brussels. Last accessed on 29/06/11 and available at http://ec.europa.eu/research/social-sciences/pdf/the-world-in-2025-report en.pdf

9. Givaudan ( 2011) Sustainability, translating vision into action. Last accessed on 29/06/11 and available at www.givaudan.com

10. E.Göll, (in press) Futur - the Research Dialogue in Germany. In Exploring the future The role of interaction in foresight. Borch et al (eds.) Edward Elgar Cheltenham, UK.

11. L.A. Pace, (in press) Strategic Planning for the Future: Malta's eFORESEE Experience. In Exploring the future The role of interaction in foresight. Borch et al., (eds.) Edward Elgar Cheltenham, UK.

12. PBL \& Stockholm Resilience Centre (2009) Getting into the Right Lane for 2050. Netherlands Environmental Assessment Agency (PBL), Bilthoven, NL. Last accessed on 29/06/11 and available at www.pbl.nl/en

13. M.S. Jørgensen, (in press) Case Denmark Green Technology Foresight, Phase 1. In Exploring the future The role of interaction in foresight. Borch et al., (eds.) Edward Elgar Cheltenham, UK

14. S.Stalpers, C. Kroeze (in press) Dialogues in the COOL Project. In Exploring the future The role of interaction in foresight. Borch et al., (eds.) Edward Elgar Cheltenham, UK.

15. UNEP/RIVM (2003). Four scenarios for Europe. Based on UNEP's third Global Environment Outlook. Last accessed on 29/06/11 and available at http://www.unep.org/geo/GEO3/pdfs/four scenarios europe.pdf

16. VLM (2009) Buiten de lijnen. Vlaamse Land Maatschappij, Brussel. Last accessed on 29/06/11 and available in Dutch at http://www.vlm.be/SiteCollectionDocuments/Publicaties/Platteland/VLM brochure DEF.pdf

17. WBCSD (2010) Vision 2050: The new agenda for business. World Business Council for Sustainable Development, Washington. Last accessed on 29/06/11 and available at http://www.wbcsd.org/web/vision2050.htm. 


\section{Vitae}

Peter De Smedt has a background in ecological system analyses. His professional challenge is connecting science and policy. On a broad range of regional and EU projects, involving foresight and integrated assessment, Peter worked together with experts and stakeholders towards achieving a common understanding on non-sustainable trends, offering scenarios and integrated solutions to support policy-makers. Currently Peter works at the Research Centre of the Flemish Government where he is in charge of foresight and sustainability assessment.

Kristian Borch has a background in biochemistry and conflict management. His field of interest is sociotechnological aspects such as uncertainty, ethics and sustainability, of emerging technologies mainly inside agriculture, food production, biotechnology and bioenergy. Furthermore, he is an expert in foresight and scenario methodologies, where his interests are focused on how to handle trans-disciplinary conflicts and scientific uncertainty. Currently Kristian is Head of Section in the Department of Management Engineering (DTU Man) at the Technical University of Denmark.

Ted Fuller is a business academic and currently Director of Research for the Faculty of Business and Law at the University of Lincoln (UK). He is Professor of Entrepreneurship and Strategic Foresight. His academic mission is to understand how futures are created, to investigate society's relationship with the future and to develop responsible people who can create futures. 